\title{
The Smart City Ecosystem as an Innovation Model: Lessons from Montreal
}

\section{Mohamed Reda Khomsi}

\author{
"Montreal is a marvelous city. A large beautiful" \\ city. We need to say it. We need to show it. \\ Dennis Martinez \\ Professional baseball player \\ Montreal Expos (1986-1993)
}

\begin{abstract}
Innovations are not confined to new technologies designed to improve the manufacturing processes of a product or the provision of a service. In a context of postmodernity, the new innovation paradigm calls on organizations to choose the best innovation strategies for their broader purposes. Today, such strategies usually involve adopting organizational structures that enable better collaboration with the stakeholders of an ecosystem. This article focuses on the smart city of Montreal - selected as the 2016 Intelligent Community of the Year by the Intelligent Community Forum - as a model of innovation. The aim is to understand the distinction between "the smart city" and "the smart destination", despite the omnipresence of tourism projects in smart city development plans. Among the key lessons are the importance of engaging tourism stakeholders and the role of a dedicated organization to develop and implement the city's unique vision.
\end{abstract}

\section{Introduction}

Since the early 2000s, many cities around the world have undertaken initiatives to position themselves as "smart cities". Indeed, in the era of globalization and postmodernism, the smart city concept is well recognized as a means to increase the attractiveness of cities and the quality of life of citizens (Boes et al., 2015). In their efforts to engage in this initiative, cities generally seek to promote a dynamic of innovation that drives the development of products and the delivery of services through technology. However - and this comprises the main idea of this article - what is also needed are efforts to change organizational structures so as to create a culture of innovation among the various stakeholders. Indeed, some researchers consider the emergence of innovation to be highly dependent on the type of organizational dynamics at play (Enz \& Siguaw, 2003; Jones, 1996).

It appears, then, that the main challenge for smart cities today is to develop and implement models of collaboration between the different stakeholders. This challenge involves mediating between many actors, including those who are in competition against each other, in order to arrive at an organizational culture that represents the common interest as much as possible. This challenge also calls on the stakeholders of a smart city to think of new ways of collaborating.

In Canada, Montreal's smart city ecosystem is an example of innovation in collaboration and cooperation. In 2014, the city launched its Smart and Digital City Office (Bureau de la ville intelligente et numérique; villeintelligente.montreal.ca/en), whose mandate is to oversee Montreal's 2015-2017 Smart and Digital City Action Plan, which was developed following consultations with various stakeholders (among them public organizations), the private sector, and citizens. However, at the midpoint in the implementation of this plan, despite the omnipresence of tourism projects in Montreal's smart city project, few tourism stakeholders are engaged in the initiative. Thus, there is not necessarily an overlap or alignment between the "smart city" and the "smart destination". A smart city is "a well-defined geographical area, in which high technologies such as ICT, logistic, energy production, and so on, cooperate to create benefits for citizens in terms of well-being, inclusion and participation, environmental quality, intelligent development" (Dameri, 2013). In contrast, the smart destination is one that uses technology to 


\section{The Smart City Ecosystem as an Innovation Model: Lessons from Montreal}

\section{Mohamed Reda Khomsi}

guarantee sustainable development of the tourist area and to improve the experience quality of visitor (Lopez de Avila, 2015). With the smart destination approach, stakeholders work together, through a integrated platform for example, to create and facilitate a real-time tourism experience (Buhalis \& Amaranggana, 2014). However, in Montreal, tourism is considered as an economic activity like any other, due to which it is not considered to warrant its own sub-ecosystem. Thus, there is cause for reflection about how Montreal's current smart cities ecosystem may be improved.

To this end, this article pursues two objectives. First, it seeks to explain how a collaborative structure between the various stakeholders in Montreal's smart city project can, itself, become a source of innovation, given the services it might offer or its way of utilizing resources and tools. Second, the article seeks to show that the smart city concept is not necessarily interchangeable with the smart destinations concept, insofar as the intrinsic characteristics of their respective target populations, being the citizens and the tourists, are different.

The article is structured as follows. We begin by portraying the smart city ecosystem as an innovation model applied to the tourism context. Using an exploratory methodology, this perspective forms the basis for an analysis of the profiles of the stakeholders involved in the smart city project and their roles and missions. We then discuss the types of governance model and collaboration that could be envisaged between these stakeholders. Finally, we offer concluding thoughts and highlight the key lessons learned from the case.

\section{Innovation in Tourism: The Smart City Ecosystem as an Innovation Model}

Although the tourism sector has been a pioneer in the integration of new technologies, which were later adopted by other service spheres, the topic of innovation in tourism has received little research attention (Halkier et al., 2013). A literature review on tourism and innovation conducted by Hjalager (2010) demonstrated that research on the subject is still in its infancy. NadjaJanoszka and Kopera (2013) likewise highlight, through the study of barriers to innovation in tourism, that knowledge on the subject is still fragmentary and that many issues are investigated in an exploratory manner only, including the topic of the role of institutions in innovation. However, it is this dimension - concerning the structures of collaboration among the different stakeholders (Hjalager, 2010) - that ultimately determ- ines the effectiveness and efficiency of innovation processes (Lapointe et al., 2015). According to NadjaJanoskza and Kopera (2013), this lack of collaboration can be attributed to several factors including: the weak culture of innovation among tourism stakeholders, the high turnover of staff, poor change management, poor knowledge of information technology, and, last but not least, the small size of most tourism businesses.

The importance of the institutional dimension also results from the fact that tourism innovation requires the involvement of all stakeholders in the development process, particularly between the traditional players and new players, as emphasized by Aldebert, Dang, and Longhi (2010). According to these authors, the diffusion of innovation in tourism is complex given the heterogeneity of stakeholders, who must find ways of collaborating that take into account their differences. This requirement becomes even more critical when the stakeholders are concurrently engaged in an international innovation project in which collaborative arrangements must reflect variables such as the cultural dimension or the public policies of each participating country (Williams \& Show, 2011). In this context, several modes of collaboration between stakeholders have been proposed by researchers, among them Lapointe, Guimont, and Sévigny (2015), who point to a living lab as an effective way to bring together stakeholders around a common project with a view to achieving a common goal.

In the same vein, the smart cities ecosystem is also a good example of a mode of innovation through collaboration and adaptation of organizational structures at the city scale. Indeed, the institutional dimension is even a cornerstone in definitions proposed for the smart city concept. Nam and Prado (2011), for example, consider the smart city to revolve around three dimensions - technological, human, and institutional - and posit that innovation is crucial in particular for the institutional dimension. According to Komninos (2002), the smart city requires the implementation of good practices in a given territory with the aim of stimulating innovation, learning, and knowledge transfer between stakeholders. In the same vein, Glaeser and Berry (2006) and Nam and Prado (2011) believe that the dynamics of smart city projects can stimulate creativity, innovation, and knowledge development. For other scholars, such as Dameri (2013) and Lamfus and AlzuaSorzabal (2013), a model of partnership between the stakeholders is, itself, one form of innovation in the smart city context. These authors argue that the new 


\section{The Smart City Ecosystem as an Innovation Model: Lessons from Montreal}

\section{Mohamed Reda Khomsi}

economy requires the stakeholders of a smart city to review their practices and partnership models. In tourism, such a model is even more important considering the number of players in this sector. In order to add value for users, citizens, and visitors, all tourism stakeholders should therefore be part of the ecosystem (Lamfus et al., 2013). To achieve its objectives, the smart city needs to implement an organizational structure for optimizing the use of data and to support the creation of a favourable context for tourism stakeholders.

\section{The Montreal Smart City Ecosystem}

Before embarking on its own smart city project, Montreal conducted a comparative analysis of seven other smart cities around the world (Arlington, Barcelona, Columbus, Eindhoven, Lyon, New York, and Toronto) in order to identify best practices in smart cities (BVIN, 2015). After this exercise, the committee in charge of this analysis identified six key areas that were to form the strategic framework for the Montreal smart city project: urban mobility, direct services to citizens, living environment, democracy, sustainable development, and economic development. The strategic framework was first presented at several public consultations attended by 203 people in total. At the end of this process, 70 projects were selected from five focus areas for the Montreal Smart and Digital City Action Plan developed for the years 2015-2017 (BVIN, 2015).

Although no one industry sector was prioritized, the projects thus far implemented as part of the 2015-2017 Action Plan have had a direct effect on the city's visitors and therefore on the city's tourism sector. One example is the project of deploying Wi-Fi terminals in the tourism district of Old Montreal. The project goal is to enhance the experience of citizens and visitors in order to boost tourism activity and accelerate the economic development of Montreal. The project will, in turn, allow the city to realize a larger app-based project called Montréal en histoire, which offers a trip back in time through 60 points of interest in augmented reality. The project will feature images of prominent figures who have contributed to the history of Montreal to be projected on the walls, ground, and vegetation in Old Montreal and to be accompanied with an audible soundtrack through the app. This app was also an important selling point for Montreal's selection as the 2016 Intelligent Community of the Year by the Intelligent Community Forum (ICF, 2016). The ICF is a nonprofit organization based in New York that studies the development of cities in the 21st century. Mainly centered on research, conferences, consulting services, educational services, and an annual competition, it identifies best practices in the development of smart cities (Mathys, 2016).

The international recognition of Montreal as a smart city model is also attributed to its unique and innovative ecosystem in which citizens are given the opportunity to participate. Indeed, whether through social networks, digital platforms or citizen forums, such as Je vois Montréal - a platform of dynamic tools to help citizens mobilize and collaborate to make Montreal an inspiring city - citizens do contribute very actively to the process. As described below, the Montreal ecosystem is built around the three dimensions: governance, districts, and entrepreneurship.

1. Governance: The Smart and Digital City Office, dedicated to Montreal's smart city, promotes a coherent development strategy and consistency of actions taken by the various stakeholders. At the administrative level, this separate administrative structure within the municipal bureaucracy is also one where decisions can be made relatively fast and with a certain degree of fluidity. Since its inception, the Office has been dedicated to making Montreal a world leader in the field by 2017 - the year when Montreal celebrates its 375th anniversary (BVIN, 2015).

2. Districts: Montreal is known for its theme-based city districts that position themselves as incubators of innovation. Among these are the Quartier de l'innovation (innovation district) (quartierinnovationmontreal.com) and the Quartier des spectacles (entertainment district). The innovation district is a living laboratory created in 2013 by three Montreal universities (McGill University, École de technologie supérieure, and Concordia University) and is a showcase of innovation, research, training, and entrepreneurship. A few months after its launch, the three universities that initiated the project created an organization that manages the initiatives generated within the district. The board of directors of this organization is composed of business people who add real value to the district, either through project financing or property management in partnership with other public or private partners. For managers of the district, the mission of the project boils down to three goals (QI, 2015): to attract more technological, social, and cultural companies; to foster the development of innovative initiatives; and to promote innovation with the targeted implementation of activities. From 2014 to 2015 alone, the 


\section{The Smart City Ecosystem as an Innovation Model: Lessons from Montreal}

\section{Mohamed Reda Khomsi}

innovation district saw the establishment of offices by several technology companies, including Google, with the district's companies also receiving investments of more than $\$ 46$ million during that same time period (QI, 2015).

The Quartier des spectacles (entertainment district) (quartierdesspectacles.com) is a hub of cultural creation and entertainment that has more than 30 theatres; three squares dedicated to festivals and cultural events; and a number of larger buildings such as the Montreal Symphony House, the Théâtre du Nouveau Monde, and several luxury hotels - all within one square kilometre. In all, the entertainment district presents a diverse offering of over 100 shows every month, thereby contributing to the economic development of the metropolis and its international profile. At the organizational level, a non-profit organization called the Quartier des Spectacles Partnership was created in 2003 to coordinate the actions of the various players operating in this district. Eventually, and after the initial development work and obtaining site recognition from the public actors, this organization has seen its mission expand to include the coordination and management of the three squares, which are now considered tourism destinations.

3. Entrepreneurship: The dynamism of Montreal with regard to creativity, innovation, and an environment conducive to entrepreneurship allowed the city to attract several technology companies that make up the backbone of its smart city concept. Here, InnoCité (innocitemtl.ca), which is the first accelerator program in Canada focused on the smart city concept, has been instrumental in sponsoring projects that promise to bring an added value to the city. InnoCité mentors investment funds and employers with a view to providing comprehensive support to project leaders. In addition to InnoCité, the city can count on the contribution of the four universities on its territory, each of which has a mentoring program for a living lab and a structured business start-up support service.

\section{Discussion and Conclusion}

Despite the ubiquitousness of the tourism dimension in Montreal's smart city project, the city's tourism stakeholders are hardly engaged in the effort of turning the city into a true smart destination. For example, although Montreal's tourism bureau (Tourisme Montréal; tourisme-montreal.org) was, in 2009, among the first destination management organizations in North America to invest $100 \%$ of its promotional budget into its online presence (Ciotola, 2010), it was not directly involved in consultations aimed at developing an action plan for the smart city. Moreover, aware of the smart destination trend, Tourisme Montréal did take the initiative to redesign its digital infrastructure with the aim to, through the use of big data, find out more about the area's visitors. However, despite this project, commenced a long time before the founding of the Smart and Digital City Office, Montreal's tourism bureau has only a minor role in defining the new vision of the city. Thus, the tourism governance structure in Montreal is not in step with the shift undertaken by the city.

That said, this situation is not unique to Montreal. According to Giffinger and Gudrun (2010), Cohen (2011), Cocchia (2014), and Galoul (2015), the relationship between the concept of a smart city and that of a smart destination is blurred. In general, the scientific literature makes no distinction between the two, such that a smart destination is by default integrated in the smart city concept. However, as pointed out by Buhalis and Amaranggana (2014) and Boes, Buhalis, and Inversini (2015), technologies used in a smart destination are fundamentally different from those used in a smart city. For example, the authors state that tourists use technology before, during, and after a trip, whereas the technology implemented in a smart city revolves around its use within the city.

In addition to the technological dimension, we believe that the difference between the smart city and smart destination manifests on at least two levels. First, in the case of tourists visiting a destination for a limited time, temporal and informational needs play an important role. They want to enjoy themselves during their stay and need an application that can help them optimize the little time they have. The second difference is related to space. Indeed, the tourist visiting a destination for the first time does not have the same spatial references as a resident with regard to the use of the territory. In an urban setting, the tourist is often confined to a limited area. In Montreal for instance, as in many large cities, the main tourist attractions are concentrated in the downtown area (Pilette \& Kadri 2005), where traffic is very dense. In this context, tourists' informational needs are high because they need to learn about places to visit, travel options, costs, and access times. By contrast, the needs and expectations of residents living in the city on a longer-term basis are much lower in this regard. 


\section{The Smart City Ecosystem as an Innovation Model: Lessons from Montreal}

\section{Mohamed Reda Khomsi}

In the case of Montreal, tourism stakeholders would do well to become more involved in the ecosystem of the smart city, or even to create their own system that would reflect the needs of visitors, as these often differ from those of residents. However, overall, and in comparison with other Canadian cities, Montreal's ecosystem can be described as innovative. For example, the creation of an organizational structure dedicated solely to the smart city helped to spawn initiatives within the innovation and entertainment districts and promoted entrepreneurship by linking up startups with funding bodies. Moreover, Montreal's Smart and Digital City Office also gives it an advantage over other cities in Quebec such as Quebec City and Sherbrooke. In the case of Sherbrooke, the municipal administration launched the smart city initiative in 2012 with the goal to create a dynamic partnership and to mobilize local stakeholders around a common vision (CEFRIO, 2012). These efforts have resulted in the establishment of a round table for Sherbrooke's smart and innovative city. However, the absence of a specific organization dedicated for developing the smart city project has resulted in postponement of the implementation of the smart city policy until 2017.

Finally, the case study of Montreal teaches us at least two key lessons. First, the existence of an entity dedicated to developing the vision of the smart city is a powerful accelerator for projects that may be proposed by the various stakeholders of the ecosystem. The dedicated structure helps coordinate the activities of different players and ensures that these projects fit in with the vision of the smart city. Second, despite the innovative nature of the Montreal smart city ecosystem, the connection with the vision for Montreal as a smart destination is not automatic. For others wishing to improve tourism experiences, this case reinforced the importance of engaging tourism stakeholders given that the needed tools, developed as part of the smart city, are promoted outside traditional tourism distribution channels.

\section{About the Author}

Mohamed Reda Khomsi is a Professor of Tourism Governance and E-Tourism at the Department of Urban Studies and Tourism in the School of Management at the Université du Québec à Montréal, Canada. His research focuses on smart destinations, online distribution, governance models, and the assessment of the hallmark tourist event. Mohamed is the author of over a dozen articles and book chapters on these topics. He is currently investigating various examples of smart cities and smart destinations in Canada with the aim to highlight the particular features of the Canadian model.

\section{References}

Aldebert, B., Dang, R., \& Longhi, C. 2011. Innovation in the Tourism Industry: The Case of Tourisme@. Tourism Management, 32(5): 1204-1213.

http://dx.doi.org/10.1016/j.tourman.2010.08.010

Boes, K., Buhalis, D., \& Inversini, A. 2015. Conceptualising Smart Tourism Destination Dimensions. In L. Tussyadiah \& A. Inversini (Eds.), Proceedings of the International Conference on Information and Communication Technologies in Tourism: 391-404. Switzerland: Springer International Publishing. http://dx.doi.org/10.1007/978-3-319-14343-9_29

Buhalis, D., \& Amaranggana, A. 2014. Smart Tourism Destinations. In Z. Xiang \& L. Tussyadiah (Eds.), Proceedings of the International Conference on Information and Communication Technologies in Tourism: 553-564. Switzerland: Springer International Publishing. http://dx.doi.org/10.1007/978-3-319-03973-2_40

BVIN. 2015. Montreal Smart and Digital City Action Plan 2015-2017. Montreal: Bureau de la ville intelligente et numérique (BVIN); City of Montreal.

http://villeintelligente.montreal.ca/en/action-plan-2015-2017

CEFRIO. 2012. Sherbooke innovante et intelligente - Phase 1. Centre facilitant la recherche et l'innovation dans les organisations (CEFRIO). Accessed November 1, 2016: http://www.cefrio.qc.ca/projets-recherches-enquetes/numeriqueterritoires/prijet-sherbrooke-innovante-et-intelligente-phase-1/

Ciotola, C. 2010. Online Brand for Destination E-Branding Monitoring. Paper presented at the ENTER eTourism Conference, February 10-12, 2010, Lugano, Switzerland.

Cocchia, A. 2014. Smart and Digital City: A Systematic Literature Review. In R. P. Dameri \& C. Rosenthal-Sabroux (Eds.), Smart City: How to Create Public and Economic Value with High Technology in Urban Space: 13-43. Berlin: Springer.

http://dx.doi.org/10.1007/978-3-319-06160-3_2

Cohen, H. 2011. Social Media Definitions. Heidi Cohen: Actionable Marketing Guide, May 9, 2011. Accessed November 1, 2016: http://heidicohen.com/social-media-definition/ 


\section{The Smart City Ecosystem as an Innovation Model: Lessons from Montreal}

\section{Mohamed Reda Khomsi}

Dameri, R. P. 2013. Searching for Smart City Definition: A Comprehensive Proposal. International Journal of Computers \& Technology, 11(5): 2544-2551.

Enz, C. A., \& Siguaw, J. A. 2003. Innovations in Hotel Practice. Cornell Hotels and Restaurant Administration Quarterly, 44(4/5): 115-123. http://dx.doi.org/10.1177/001088040304400516

Galoul, A. 2015. Les villes intelligentes: l'open data contribue-t-il à leur développement? Louvain, Belgium: Louvain School of Management, Université catholique de Louvain.

Glaeser, E. L. \& Berry, C. 2006. Why Are Smart Places Getting Smarter? Policy Brief 2-2006. Boston, MA: Rappaport Institute/Taubman Center.

Giffinger, R., \& Gudrun, H. 2010. Smart Cities Ranking: An Effective Instrument for the Positioning of Cities? ACE: Architecture, City and Environment, 4(12): 7-25.

Hjalager, A.-M. 2010. A Review of Innovation Research in Tourism. Tourism Management, 31(1): 1-12.

http://dx.doi.org/10.1016/j.tourman.2009.08.012

Halkier, H., Kozak, M., \& Svensson, B. 2014. Innovation and Tourism Destination Development. European Planning Studies, 22(8): 1547-1550.

http://dx.doi.org/10.1080/09654313.2013.784571

ICF. 2016. Intelligent Community of the Year 2016: Montreal, Quebec, Canada. Intelligent Community Forum (ICF). Accessed November 1, 2016:

http://www.intelligentcommunity.org/ic_of_year

Jones, P. 1996. Managing Hospitality Innovation. Cornell Hotel and Restaurant Administration Quarterly, 37(5): 86-95. http://dx.doi.org/10.1177/001088049603700528
Komninos, N. 2002. Intelligent Cities: Innovation, Knowledge Systems and Digital Spaces. London: Spon Press.

Lamsfus, C., \& Alzua-Sorzabal, A. 2013. Theoretical Framework for a Tourism Internet of Things: Smart Destinations. tourGUNE: Journal of Tourism and Human Mobility, 0: 15-21.

Lapointe, D., Guimont, D., \& Sévigny, A. 2015. The Living Lab Approach to Raise Innovation Capability Among Tourism Practitioners. Tourism Dimension, 2(2): 18-27.

Lopez de Avila, A. 2015. Smart Destinations: XXI Century Tourism. Presented at the ENTER2015 Conference on Information and Communication Technologies in Tourism, February 4-6, 2015, Lugano, Switzerland.

Najda-Janoszka, M., \& Kopera, S. 2013. Exploring Barriers to Innovation in Tourism Industry - The Case of Southern of Poland. Procedia - Social and Behavioral Sciences, 110: 190-201. http://dx.doi.org/10.1016/j.sbspro.2013.12.862

Nam, T., \& Prado, T. 2011. Conceptualizing Smart City with Dimensions of the Technology, People, and Institutions. In Proceedings of the 12th Annual International Conference on Digital Government Research: 282-291. https://doi.org/10.1145/2037556.2037602

Pilette, D., \& Kadri, B. 2005. Le tourisme métropolitain. Le cas de Montréal. Montréal: Presses de l'Université du Québec.

QI. 2015. Annuel report 2014-2015. Montreal: Quartier de l'innovation (QI).

Williams, A. M., \& Shaw, G. 2011. Internationalization and Innovation in Tourism. Annals of Tourism Research, 38(1): 27-51. http://dx.doi.org/10.1016/j.annals.2010.09.006 